\title{
Uso da plataforma web Google Classroom como ferramenta de apoio à metodologia Flipped Classroom: relato de aplicação no curso de Bacharelado em Sistemas de Informação
}

\author{
Lucas Ferreira Mendes ${ }^{1}$, Nicolas Oliveira Amorim² \\ ${ }^{1}$ Instituto Federal de Educação, Ciência e Tecnologia do Ceará - Campus Cedro \\ ${ }^{2}$ Núcleo de Informação e Comunicação - Prefeitura Municipal de Tauá - CE. \\ lucas.mendes@ifce.edu.br, nicolas.oliveira.amorim@gmail.com
}

\begin{abstract}
There is a great effort to use Digital Information and Communication Technologies resources within the teaching-learning process. In this context, the present work aimed to analyze how the use of the online learning management platform Google Classroom can contribute to the application of the collaborative learning methodology Flipped Classroom. A case study was carried out, whose data were obtained through participant observations and an electronic questionnaire made available to the students. With the data obtained through the observations and the questionnaire, it was possible to verify that the Flipped Classroom methodology was well accepted by the students and that the use of the Google Classroom web platform enhanced the interaction and collaboration between them.
\end{abstract}

Resumo. Existe um grande esforço em utilizar recursos das Tecnologias Digitais da Informação e Comunicação dentro do processo de ensinoaprendizagem. Nesse contexto, o presente trabalho teve como objetivo analisar como o uso da plataforma de gerenciamento de aprendizagem online Google Classroom pode contribuir para a aplicação da metodologia ativa de aprendizagem colaborativa Flipped Classroom. Realizou-se um estudo de caso, cujos dados foram obtidos através de observações participantes e de um questionário eletrônico disponibilizado aos alunos. Com os dados obtidos por meio das observações e do questionário, foi possível constatar que a metodologia Flipped Classroom foi bem aceita pelos alunos e que o uso da plataforma web Google Classroom potencializou a interação e colaboração entre os mesmos.

\section{Introdução}

Segundo a revista [Ensinoinovativo 2015], o modelo tradicional de ensino tem como principal foco a assimilação do conteúdo, por não considerar o desenvolvimento de habilidades e competências em seu escopo. Em oposição a isso, a tecnologia possibilita que o aluno obtenha informações sem a intermediação do professor. As Tecnologias Digitais da Informação e Comunicação (TDICs) têm um papel fundamental na transição do modelo tradicional de ensino para o modelo de ensino ativo, centrado no aluno e buscando que este seja o ator principal no processo de aprendizagem.

$\mathrm{O}$ uso de ferramentas tecnológicas associadas às metodologias ativas de 
VIII Congresso Brasileiro de Informática na Educação (CBIE 2019)

Anais do XXV Workshop de Informática na Escola (WIE 2019)

aprendizagem colaborativa, possibilitam a troca de ideias, entre si e entre os grupos, propiciando a construção do aprendizado coletivo e em equipe, sendo as habilidades desenvolvidas de forma o mais natural possível, sob o gerenciamento do professor [Tajra 2001 apud Gianotto and Diniz 2010].

Nesse contexto, a metodologia Sala de Aula Invertida ou Flipped Classroom (FC), é uma metodologia ativa e colaborativa, onde o ambiente educacional é centrado no aluno e não mais no professor, que nesse caso passa a ser um facilitador de aprendizagem, guiando o estudo e gerenciando as atividades da equipe de aprendizagem. Visto isso, o presente trabalho teve como objetivo analisar como o uso da plataforma web Google Classroom pode contribuir para a aplicação da metodologia ativa de aprendizagem colaborativa Flipped Classroom e a percepção dos alunos quanto a sua utilização. O estudo foi feito em duas turmas do curso de Bacharelado em Sistema de Informação de uma instituição pública de ensino. O Google Classroom foi escolhido por ser uma ferramenta simples, colaborativa, gratuita e que permite o desenvolvimento de um ambiente ubíquo de aprendizagem.

Este artigo está organizado em 6 seções. A seção 2 apresenta os conceitos sobre metodologias ativas de ensino-aprendizagem e sua relação com o uso de TDICs, abordando as metodologias de aprendizagem colaborativa e o modelo FC; a seção 3 apresenta uma abordagem das características e possibilidades da plataforma web Google Classroom; a seção 4 apresenta os métodos e procedimentos utilizados durante a execução das atividades; a seção 5 apresenta os resultados e as discussões sobre os mesmos e a seção 6 apresenta as considerações finais.

\title{
2. Metodologias ativas de ensino-aprendizagem com uso de TDICs
}

O modelo tradicional de ensino traz o professor como o protagonista do processo de ensino-aprendizagem, sendo um modelo centrado na transmissão de conteúdo ao aluno, de forma sistemática e organizada, devendo este ser memorizado e reproduzido em avaliações futuras. Dessa maneira o aluno está limitado ao que o professor planeja e executa em sala de aula, tornando-se um ser passivo, sem criticidade, criatividade e inibições. [Freire 2016] afirma que:

\begin{abstract}
saber ensinar não é transferir conhecimento, mas criar as possibilidades para a sua própria produção ou a sua construção. Quando entro em uma sala de aula devo estar sendo um ser aberto a indagações, à curiosidade, às perguntas dos alunos, a suas inibições, um ser crítico e inquiridor, inquieto em face da tarefa que tenho - a ele ensinar e não a de transferir conhecimento. [FREIRE 2016]
\end{abstract}

Em contraste a isso, as metodologias ativas se configuram como um modelo de ensino onde o professor deixa de ser o detentor primário do conhecimento e passa a ser um intermediador, um facilitador de aprendizagem. Nesse contexto o aluno é o protagonista do seu aprendizado passando a ter uma postura ativa, tendo o professor como orientador e tutor.

$\mathrm{Na}$ sociedade tecnológica em transformação, as formas de relacionamento, comunicação e de interação mudaram e isso se reflete também em sala de aula. Os estudantes atuais são provenientes de uma sociedade em transformação, com características de imediatismo, tecnológica e conectada [Schneiders 2018]. Corroborando com esse pensamento, [Kenski 2015] afirma que as tecnologias, "quando 
VIII Congresso Brasileiro de Informática na Educação (CBIE 2019)

Anais do XXV Workshop de Informática na Escola (WIE 2019)

bem utilizadas, provocam a alteração dos comportamentos de professores e alunos, levando ao melhor conhecimento e maior aprofundamento do conteúdo estudado".

\subsection{Metodologias de aprendizagem colaborativa}

As metodologias de aprendizagem colaborativa proporcionam um ambiente de construção colaborativa do conhecimento, podendo ser sustentadas e apoiadas pelo uso de algum sistema informatizado de colaboração. A tecnologia aliada a aprendizagem colaborativa pode potencializar as situações em que professores e alunos pesquisem, discutam e construam individualmente e coletivamente seus conhecimentos [Gomes et al. 2002 apud Souza and Souza 2016]. A construção colaborativa do conhecimento requer uma participação mais ativa dos alunos para que estes possam aprender juntos, buscando respostas e artefatos que os auxilie a construir o aprendizado colaborativo entre o grupo, por intermédio do professor orientador.

As metodologias ativas favorecem o aprendizado em grupo quando possibilitam um ambiente colaborativo e interdependente para a resolução dos problemas e para atingir os objetivos propostos pelo professor. Nesse aspecto destacam-se metodologias como a Aprendizagem Baseada em Problemas (ABP), Peer Instruction (PI) e o modelo de Sala de Aula Invertida, sendo essa última o foco deste trabalho.

\subsection{Sala de Aula Invertida ou Flipped Classroom}

A Sala de Aula Invertida ou Flipped Classroom (FC) pode ser entendida como uma estratégia de inversão da lógica organizacional dos acontecimentos em um processo de ensino-aprendizagem tradicional. O conteúdo da aula é disponibilizado aos alunos antes da aula presencial para que os mesmos possam estudá-lo, através de vídeos ou outras mídias digitais. O tempo da aula presencial, então, é utilizado de forma dinâmica e interativa na realização de atividades em grupo, discussões, debates, testes avaliativos, práticas de laboratório, etc.

Dessa forma o professor passa a atuar como um tutor e orientador da turma e os alunos adquirem uma postura mais ativa e responsável frente a seu processo de aprendizagem. Segundo [Valente 2014]:

a inversão ocorre uma vez que no ensino tradicional a sala de aula serve para o professor transmitir informação para o aluno que, após a aula, deve estudar o material que foi transmitido e realizar alguma atividade de avaliação para mostrar que esse material foi assimilado. $\mathrm{Na}$ abordagem da sala de aula invertida, o aluno estuda antes da aula e a aula se torna o lugar de aprendizagem ativa, onde há perguntas, discussões e atividades práticas. [VALENTE 2014]

O Quadro 1 mostra uma comparação das atividades realizadas em ambos os modelos de sala de aula, tradicional e sala de aula invertida:

Quadro 1. Comparativo entre os modelos tradicional e Flipped Classroom. 
VIII Congresso Brasileiro de Informática na Educação (CBIE 2019)

Anais do XXV Workshop de Informática na Escola (WIE 2019)

\begin{tabular}{|c|c|c|}
\hline $\begin{array}{c}\text { MODELO } \\
\text { TRADICIONAL }\end{array}$ & $\begin{array}{l}\text {-Transmissão de informação e } \\
\quad \text { conhecimento } \\
\text {-Professor palestrante } \\
\text {-Aluno passivo }\end{array}$ & $\begin{array}{l}\text {-Exercícios } \\
\text {-Projetos } \\
\text {-Trabalhos } \\
\text {-Solução de problemas }\end{array}$ \\
\hline $\begin{array}{c}\text { FLIPPED CLASSROOM } \\
\text { (FC) }\end{array}$ & $\begin{array}{l}\text {-Exercícios } \\
\text {-Debates } \\
\text {-Projetos } \\
\text {-Trabalhos } \\
\text {-Solução de problemas } \\
\text {-Professor como orientador e tutor } \\
\text {-Aluno ativo }\end{array}$ & $\begin{array}{l}\text {-Leitura } \\
\text {-Vídeos } \\
\text {-Pesquisas } \\
\text {-Busca de materiais alternativos }\end{array}$ \\
\hline
\end{tabular}

Fonte: Adaptado de Schneiders (2018).

Com base no Quadro 1, pode-se observar que o tempo em sala de aula, no modelo FC, é melhor aproveitado pois possibilita que o professor identifique as dificuldades dos alunos de forma mais precisa e rápida, podendo assim orientá-los e ajudá-los a compreender bem o assunto da aula.

\section{Google Classroom}

Para dar suporte à correta aplicação do modelo Flipped Classroom, se torna indispensável o uso de alguma ferramenta tecnológica, como uma plataforma online de gestão de aprendizagem ou Learning Management System (LMS). Souza e Souza (2016) afirmam que os sistemas LMS são plataformas que disponibilizam funcionalidades para auxílio no aprendizado online e que as suas funcionalidades possibilitam gerenciar, controlar e acompanhar o processo de aprendizagem dos alunos.

O Google Classroom é uma plataforma web online que simula uma sala de aula virtual oferecendo vários recursos para que os professores e alunos possam ingressar em um ambiente de ensino-aprendizagem colaborativo e interativo. Dessa forma a plataforma se configura como um LMS, porém não necessita de instalação local ou um servidor dedicado [Souza and Souza, 2016].

Outro ponto de destaque se encontra no fato do Google Classroom, por fazer parte de um conjunto de aplicações desenvolvidas e disponibilizadas pelo Google conhecido como G Suite for Education, possui integração com as demais aplicações: Gmail, Google Agenda, Google Drive, Google Forms, Hangouts entre outros. Assim, a gama de possibilidades que o professor tem para preparar, gerenciar e avaliar o ambiente de aprendizagem de seus alunos é muito maior.

Ao postar um material no Google Classroom, a plataforma cria um link direto com o Google Drive e os materiais são salvos em nuvem na pasta da turma. Além disso, a plataforma permite criar atividades de diferentes estilos, desde perguntas até testes avaliativos com integração ao Google Forms. Essa última permite ao professor, por exemplo, criar e aplicar uma avaliação online contando com o recurso de correção automática de testes, disponível pela plataforma.

As principais funcionalidades do Google Classroom que são: criação de turmas virtuais; lançamento de comunicados; criação de avaliações; receber os trabalhos dos 
VIII Congresso Brasileiro de Informática na Educação (CBIE 2019)

Anais do XXV Workshop de Informática na Escola (WIE 2019)

alunos; organização de todo material de maneira facilitada e otimização da comunicação entre professor e aluno [Daudt 2015 apud Souza and Souza 2016].

\section{Metodologia Adotada}

A pesquisa se configura como exploratória com enfoque qualitativo, pois visa, segundo [Sampieri 2006], examinar um tema ou problema de pesquisa pouco estudado, do qual se tem muitas dúvidas ou não foi abordado antes ou, ainda, estudá-lo sob uma nova perspectiva. A finalidade é identificar como o uso da plataforma web Google Classroom pode auxiliar a aplicação da metodologia Flipped Classroom e qual a percepção dos alunos em sua utilização.

Além disso, esse trabalho faz uso de um estudo de caso, no intuito de observar e analisar o comportamento dos alunos e sua participação em sala de aula. Também foi utilizado um questionário online como instrumento de coleta de dados junto aos alunos, sem a identificação dos sujeitos da pesquisa e sem o objetivo de obter um conhecimento generalizável. O estudo de caso foi realizado no Instituto Federal de Educação, Ciência e Tecnologia - Campus Cedro, tomando como participantes da pesquisa os alunos das disciplinas de Sistemas Distribuídos e Sistemas Operacionais, do curso de Bacharelado em Sistemas de Informação, e teve duração de quatro semanas.

A primeira etapa consistiu em elaborar uma estratégia para a utilização do modelo Flipped Classroom, onde foi planejado uma sequência didática para a aplicação do mesmo com suporte da plataforma Google Classroom, que pode ser visualizada na Figura 1. Pode-se perceber a sequência cronológica de acontecimentos das ações dentro do modelo FC e a utilização da plataforma web. Para complementar o modelo FC, foi utilizada a metodologia de Just-in-Time Teaching, ou Ensino sob Medida (EsM), que tem como ponto principal a "possibilidade do professor planejar suas aulas a partir dos conhecimentos e dificuldades dos seus alunos, manifestadas através das respostas que eles fornecem em atividades de leitura prévias aos encontros presenciais." [Araújo and Mazur].

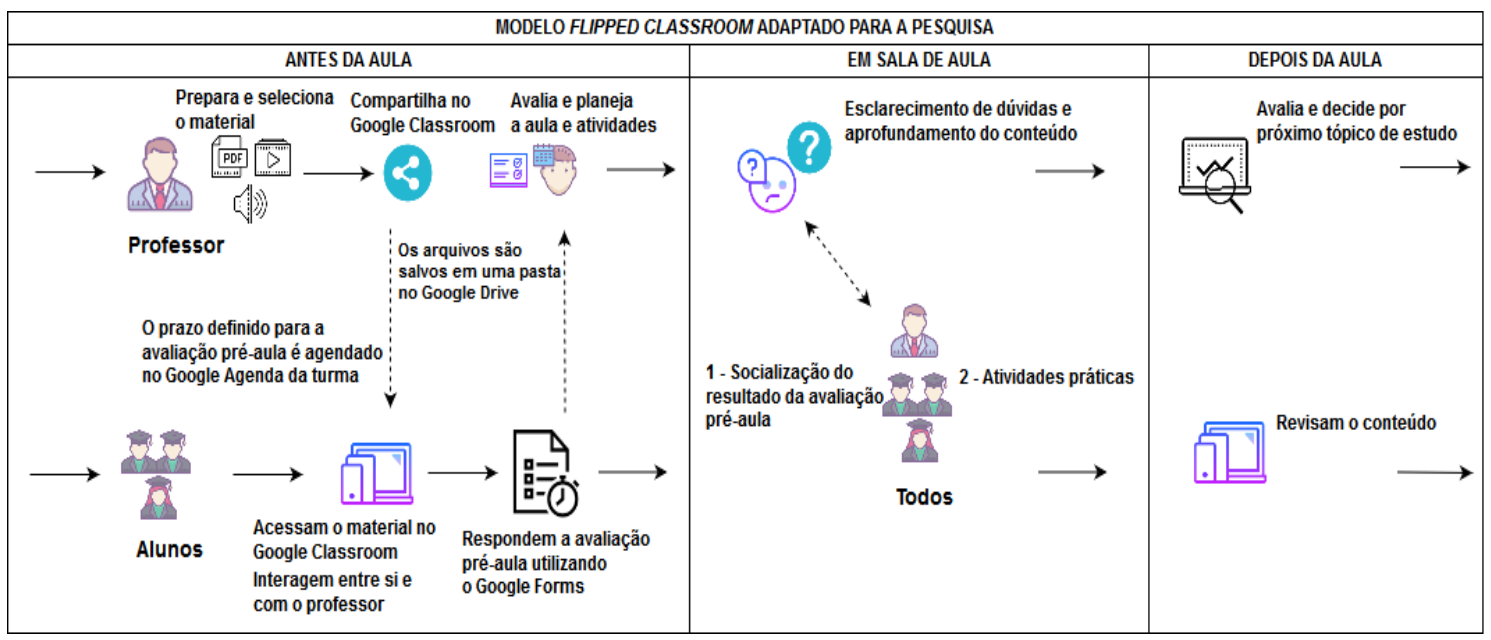

Figura 1 - Modelo FC adaptado para a pesquisa utilizando a metodologia EsM e o Google Classroom. Adaptado de Schmitz (2016). 
VIII Congresso Brasileiro de Informática na Educação (CBIE 2019)

Anais do XXV Workshop de Informática na Escola (WIE 2019)

\section{Resultados e Discussões}

O questionário foi construído em duas partes: a primeira com identificação de características socioeconômicas dos respondentes e a segunda com perguntas sobre a percepção e opinião dos alunos em relação ao estudo de caso realizado. O questionário eletrônico aplicado, obteve 28 respostas, o que configura $70 \%$ do universo de respondestes da pesquisa.

Em relação a faixa etária, gênero e localização dos respondentes, após colhidos os dados: 78,6\% dos alunos possuem idade entre 18 e 25 anos, sendo que o restante dos respondentes (21,4\%) apresenta idade entre 26 e 40 anos; $67,9 \%$ são do sexo masculino e $32,1 \%$ do sexo feminino; $67,9 \%$ dos alunos são provenientes da zona urbana, enquanto $32,1 \%$ são provenientes da zona rural.

$\mathrm{Na}$ primeira parte do questionário, também foram feitas perguntas sobre características que podem influenciar no acompanhamento da metodologia adotada e na utilização da plataforma, como: a conectividade dos alunos, se possuem computador em casa, se possuem acesso à internet em casa, entre outros. Após colhidos os dados, foi verificado que $96,4 \%$ dos respondentes possuem computador em casa e $85,7 \%$ possuem smartphone, sendo que desses últimos, $87,5 \%$ utilizam o smartphone também para estudos. Quando perguntados se possuem acesso à internet em casa, 89,3\% afirmaram que possuem. Em relação ao ambiente em que afirmaram utilizar um computador para estudo, $89,3 \%$ afirmaram utilizar o computador para estudos em casa, $64,3 \%$ na escola, $25 \%$ no trabalho em horários livres e $7,1 \%$ na Lan House, por não possuírem computador e/ou acesso à internet em casa.

Os dados supracitados mostram que a aplicação do modelo FC utilizando uma plataforma online de aprendizagem foi possível, pois a grande maioria da turma possuía os recursos necessários para a dinâmica da metodologia proposta e conseguiam acessar o conteúdo e resolver as tarefas pela plataforma.

Quando perguntados sobre o entendimento do modelo de ensino-aprendizagem Flipped Classroom e a metodologia a ser utilizada na disciplina, observou-se que $82,1 \%$ responderam que compreenderam quando apresentada pelo professor e 17,9\% afirmam ter compreendido parcialmente. Visto que o entendimento dos alunos em relação à metodologia a ser utilizada e à organização das tarefas e responsabilidades é um ponto crucial para a implementação do modelo FC, percebe-se pelos resultados supracitados que a turma, em sua grande maioria, conseguiu entender de forma satisfatória a metodologia a ser utilizada, possibilitando um bom desenvolvimento das atividades.

Em relação ao compartilhamento dos materiais de estudo prévio, os alunos foram questionados se o Google Classroom apresentava-se como um ambiente adequado para esta ação. A pergunta apresentava as alternativas em forma de escala de Likert, contendo cinco itens: do item um, discordo totalmente, ao item cinco, concordo totalmente. O Gráfico 1 mostra os resultados desta pergunta, onde observa-se que vinte e sete $(96,4 \%)$ indicaram que concordam que o Google Classroom apresenta-se como um ambiente adequado para compartilhamento dos materiais de estudo prévio.

Gráfico 1 - "O Google Classroom apresenta-se como um ambiente adequado para compartilhamento dos materiais de estudo prévio?" 
VIII Congresso Brasileiro de Informática na Educação (CBIE 2019)

Anais do XXV Workshop de Informática na Escola (WIE 2019)

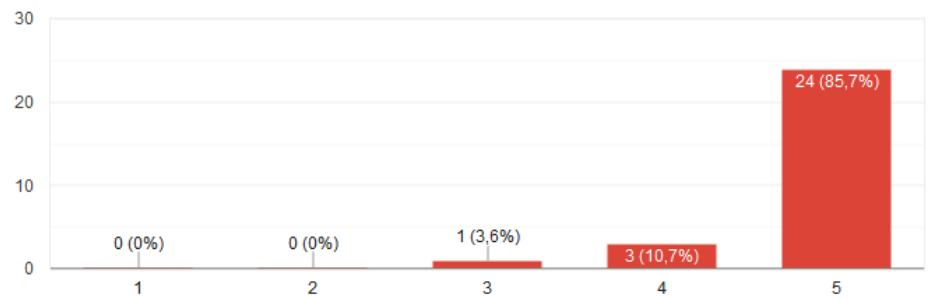

Fonte: Elaborado pelo autor.

Quando perguntados se conseguiram utilizar a plataforma em casa, 96,4\% dos respondentes afirmaram que conseguiram utilizar, sendo que apenas um $(3,6 \%)$ respondente afirmou que não conseguiu utilizar a ferramenta em casa, possivelmente $o$ mesmo que afirmou não possuir smartphone ou computador em casa, tendo que recorrer a outros espaços, como Lan House e o ambiente de trabalho, para ter acesso ao material de aula. Em relação a conseguir utilizar o Google Classroom pelo smartphone, 85,7\% afirmaram que conseguiram utilizar, enquanto $14,3 \%$ não conseguiram utilizar a ferramenta pelo dispositivo móvel. Isso mostra que, no geral, a turma não encontrou dificuldade em obter acesso ao material e em utilizar a ferramenta na etapa de estudo prévio.

Em relação a usabilidade da plataforma, os dados mostrados no Gráfico 2, mostram que $96,4 \%$ concordaram que o Google Classroom possui boa usabilidade, é intuitivo e não ofereceu dificuldade quanto a sua utilização. Isso vem de encontro com o resultado da pergunta que os questionou sobre as maiores dificuldades em utilizar a plataforma, onde apenas três pessoas $(10,7 \%)$ afirmaram ter encontrado alguma dificuldade técnica em utilizar a ferramenta. A maioria afirmou como dificuldades em utilizar a plataforma, falta de tempo para acessar o ambiente $(50 \%)$ e problemas de acesso á Internet (42,9\%).

Gráfico 2 - "A plataforma Google Classroom possui boa usabilidade, é intuitiva e não encontrei problemas em saber utilizá-la da maneira correta."

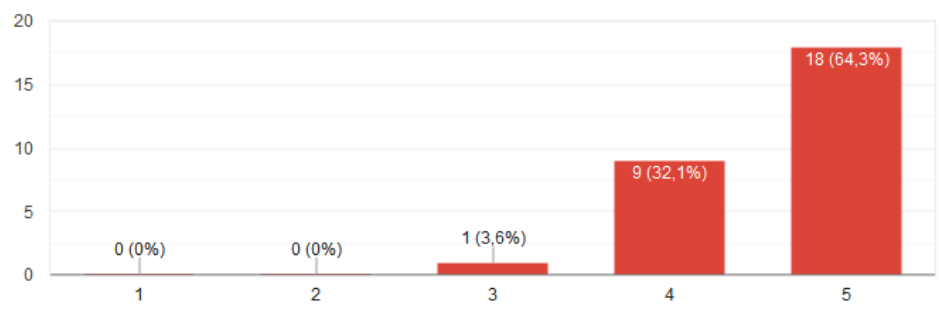

Fonte: Elaborado pelo autor.

Quanto à percepção dos alunos sobre o nível de colaboração entre os colegas da turma e à interação com o professor dentro da plataforma, os mesmos avaliaram positivamente, como mostra o Gráfico 3.

Gráfico 3 - "A plataforma permite um ambiente adequado à colaboração entre os colegas da turma?" 
VIII Congresso Brasileiro de Informática na Educação (CBIE 2019)

Anais do XXV Workshop de Informática na Escola (WIE 2019)

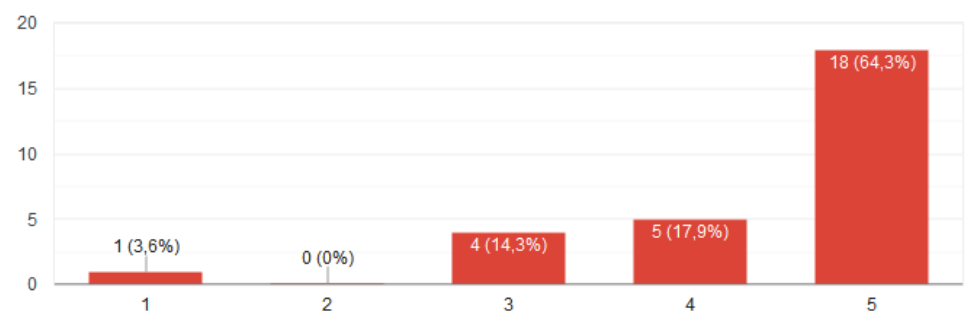

Fonte: Elaborado pelo autor.

Com base nas observações realizadas em sala, pode-se destacar que os alunos a partir do momento em que realizavam o estudo prévio e respondiam a avaliação préaula, chegavam em sala de aula com um conhecimento inicial sobre o conteúdo, demonstrando isso através de dúvidas pontuais sobre determinados assuntos do conteúdo. Isso mostra que os mesmos já vinham para aula com dúvidas formuladas, o que tornou as aulas mais dinâmicas e personalizadas às necessidades da turma.

O questionário contou também com questões abertas, para que os alunos pudessem falar com suas próprias palavras o que acharam do uso da plataforma e a experiência com a metodologia FC. O Quadro 2 apresenta uma pequena amostragem das respostas dos alunos quando questionados sobre como os mesmos avaliavam o uso do Google Forms para a realização das avaliações pré-aula, propostas pela metodologia.

Quadro 2 - "Como você avalia o uso do Google Forms para a realização das avaliações pré-aula?"

"E um método que facilita bastante as avaliações"

"Achei inovador e prático."

"É uma ótima ferramenta por que auxilia ainda mais o interesse para estudar pra determinada disciplina."

"Bem interessante principalmente no quesito de correção automática das avaliações"

“O aluno estuda o conteúdo em casa e faz uma atividade no google forms para testar o conhecimento e assim procurar aprender."

“Avalio como uma ótima ferramenta por ser prática e também por ser fácil de se usar, mesmo para quem está utilizando pela primeira vez essa ferramenta."

Fonte: Elaborado pelo autor

Quando perguntados sobre qual a percepção em relação a como o uso da metodologia Flipped Classroom pode contribuir na dinâmica da sala de aula, os mesmos citaram pontos como: "facilita a comunicação entre o professor e a sala", "proporciona uma interação entre os colegas", "Facilita muito a aprendizagem do Alunos", "Auxilia na aproximação aluno e professor", entre outros. O Quadro 3 apresenta algumas respostas à essa pergunta, onde pode-se perceber que os respondentes abordaram bastante as questões de interatividade entre aluno e professor, formulação de dúvidas facilitando o aprendizado, maior participação dos alunos em sala e melhor 
VIII Congresso Brasileiro de Informática na Educação (CBIE 2019)

Anais do XXV Workshop de Informática na Escola (WIE 2019)

aproveitamento do tempo de aula pelo professor, sendo este último o foco do modelo FC.

Quadro 3 - "Em sua percepção, como o uso da metodologia Flipped Classroom pode contribuir na dinâmica da sala de aula?"

“Auxiliar na formulação de dúvidas mais consistentes, assim o professor pode aproveitar melhor o tempo de aula."

"Contribui de forma que ao chegar nas aulas é possível obter mais resultados já que os alunos já podem ir com dúvidas a serem sanadas."

"Pode contribuir no processo de aprendizagem colocando os alunos como protagonista em um processo de aprendizagem. Nesse processo ele tem toda a autonomia necessária para adquirir novos conhecimentos e habilidades quando the for mais conveniente. Graças ao uso da tecnologia, é o próprio aluno que decide quando, como e onde eles irão aprender."

“O aluno lê o material em casa e vai com duvidas pra aula, assim a aula fica mais dinâmica."

“A principal contribuição seria na otimização da aula, pois os alunos já chegam com um conhecimento prévio do assunto da aula, e desta forma as dúvidas são sanadas mais rapidamente."

Fonte: Elaborado pelo autor

\section{Considerações Finais}

Com base nas respostas obtidas no questionário e com base nas observações realizadas durante as aulas, pode-se observar que a metodologia Flipped Classroom foi bem aceita pelos alunos e que o uso da plataforma web Google Classroom potencializou a interação e colaboração dos alunos, além de se mostrar como um ambiente adequado para o compartilhamento do material de estudo prévio e comunicação entre a turma. Também foi possível perceber que a plataforma ofereceu um ambiente de controle adequado para o professor gerenciar o ritmo de aprendizagem da turma.

A proposta de sequência metodológica que foi utilizada durante a pesquisa se mostrou eficiente pois a metodologia EsM possibilitou, com auxílio do Google Forms integrado ao Google Classroom, ao professor analisar as dificuldades encontradas pelos alunos na etapa de estudo prévio do modelo FC, e assim, planejar a aula em sala de forma mais personalizada às necessidades da turma. Dessa forma, como apontado pelos próprios alunos nas respostas ao questionário, o tempo em sala de aula pôde ser melhor aproveitado para sanar as dúvidas da turma e trabalhar atividades práticas sobre o conteúdo da aula.

Cabe destacar que a metodologia adotada com auxílio da plataforma web Google Classroom, deve ser muito bem apresentada e explicada aos alunos, pois a eficiência da mesma depende muito do entendimento e envolvimento por parte da turma.

Espera-se que esse trabalho possa contribuir na discussão do uso de metodologias ativas aliadas a ferramentas tecnológicas como forma de potencializar a eficiência no processo de ensino-aprendizagem. Como trabalhos futuros pode-se apontar um estudo comparativo da aplicação do modelo FC em diferentes plataformas web LMS 
VIII Congresso Brasileiro de Informática na Educação (CBIE 2019)

Anais do XXV Workshop de Informática na Escola (WIE 2019)

e com auxílio de diferentes metodologias, como Peer Instruction e Aprendizagem Baseada em Problemas.

\section{Referências}

Araujo, I. S. and Mazur, E. (2013). Instrução pelos colegas e ensino sob medida: uma proposta para o engajamento dos alunos no processo de ensino-aprendizagem de Física. In Caderno Brasileiro de Ensino de Física, pages 362-384.

Freire, P. (2016). Pedagogia da Autonomia. Saberes necessários à prática educativa. 53a edição, Rio de Janeiro: Paz e Terra, 2016.

Gianotto, D. E. P. and Diniz, R. E. da S. (2010). Formação inicial de professores de Biologia: a metodologia colaborativa mediada pelo computador e a aprendizagem para a docência. In Ciência \& Educação, pages 631-648.

Kenski, V. M. (2015) Educação e Tecnologias: o Novo Ritmo da Informação, Campinas, SP: Papirus, 2015.

Sampieri, R. H., Collado, C. H., and Lucio, P. B. (2006). Metodologia de pesquisa. $3^{\text {a }}$ ed. F. C. Murad (Trad.). São Paulo: McGraw-Hill, 2006.

Schmitz, E. X. da S. (2016). Sala de Aula Invertida: Uma abordagem para combinar metodologias ativas e engajar alunos no processo de ensino-aprendizagem. 2016. 187 f. Dissertação (Mestrado) - Curso de Mestrado em Tecnologias Educacionais em Rede, Universidade Federal de Santa Maria, Santa Maria, 2016.

Schneiders, L. A. (2018). O método da sala de aula invertida (flipped classroom). Lajeado: Univates, 2018. 19 p.

Souza, A. and Souza, F. (2016) Uso da Plataforma Google Classroom como ferramenta de apoio ao processo de ensino e aprendizagem: Relato de aplicação no ensino médio. 2016. 27 f. TCC (Graduação), Centro de Ciências Aplicadas e Educação, Universidade Federal da Paraíba - UFPB, Rio Tinto, 2016.

Tecnologia Inovadora (2015). Revista Ensinoinovativo. São Paulo, volume especial, 2015.

Valente, J. A. (2014). Blended learning e as mudanças no ensino superior: a proposta da sala de aula invertida. In Educar em revista [online] pages 79-97. 